\title{
CRÍtica e POÉtica PARA O APRENDIZAdo SOBRe A PAISAGEM NO ENSINO DE GEOGRAFIA
}

\author{
CRITICAL AND POETICS FOR THE LEARNING ABOUT LANDSCAPE IN THE \\ GEOGRAPHY TEACHING
}

DOI: http://dx.doi.org/10.23926/RPD.2526-2149.2018.v3.n2.p740-751.id150

\author{
João Vitor Gobis \\ Verges \\ Doutor em Geografia \\ (UNESP). \\ Doutor em Ciências do \\ Ambiente (ULisboa). \\ Professor EBTT (IFMT). \\ joao.verges@vgd.ifmt.edu.br
} Resumo: Com este artigo, apresentam-se os resultados de uma
proposta realizada no âmbito do processo de ensino-aprendizagem
sobre a paisagem, procurando ampliar a indicação do papel do
"sentimento da paisagem" como mecanismo de construção de
leituras geográficas por estudantes do ensino médio. Neste quesito,
a interpretação da paisagem como portadora de dimensões
econômicas e políticas estruturantes é complementada com a
inserção afetiva erguida através da poética, permitindo a ampliação
das exposições dos significados da paisagem para os estudantes. Para
isto, utilizou-se do desenvolvimento de aula expositiva, seguida da
propositura fotográfica dos locais de identificação afetiva, realizando
posteriormente descrições críticas das paisagem e, conjuntamente,
poesias sobre os sentimentos gerados por elas. Obteve-se, então, a
possibilidade de compreender a análise ofertada pelos discentes e
suas raízes valorativas no contexto geográfico, assentindo a
ampliação das fronteiras de entendimento entre a relação
sociedade/natureza em diferentes escalas, além de ratificar a
fotografia e poesia como caminho para o ensino de geografia.
Palavras-chave: Categorias Geográficas. Ensino-Aprendizagem. Sequência Didática.

\begin{abstract}
This paper presents the results of a proposal made in the context of the teaching-learning pro-cess on the landscape, aiming to assess the role of "landscape feeling" as a mechanism for the construction of geographic readings by secondary school students. the interpretation of the landscape as a vehicle of economic and structural policy dimensions is complemented with the built affective insertion through the poetic, allowing the expansion of the exhibition of land-scape meanings for students. for this, we used the development of lecture, followed the pro-posal in which students photographed affective identification of sites and subsequently to prepare descriptions criticism of landscape and, together poems about the feelings generated by them. was obtained, then the possibility of understanding the analysis offered by students and their evaluative roots in geographic context, on the basis of the of the boundaries of un-derstanding between the society / nature relationship at different scales, in addition to ratify-ing photography and poetry as a way to teach geography.
\end{abstract}

Keywords: Geographical Categories. Teaching-Learning. Didactic Sequence. 


\section{INTRODUÇÃO}

Este trabalho corresponde à problematização em torno do ensino de categorias geográficas na educação básica, especificamente tratando-se da paisagem. Neste processo, encaminha-se a abordagem pelos contornos histórico-críticos, apoiada na perspectiva estrutural, conjuntamente com o referencial teórico aportado nas elucubrações da poética. O texto apresentado é fruto de pesquisa sobre o ensino de Geografia, procurando aprimorar ferramentas didáticas através do uso e verificação dos resultados.

A categoria "paisagem" é central para a compreensão geográfica em múltiplas escalas, uma vez que é fundamento analítico deste ramo científico. Neste âmbito, reconhecer as ações em sociedade e as dinâmicas da natureza nos processos formativos, ou então, já delineados nas paisagens, favorece o potencial de contribuição para o ensino com intuito de orientação dos sujeitos à cidadania.

Desse modo, compõe-se o movimento investigativo a partir de dois caminhos norteadores: como estruturar uma aula apoiada no "sentimento da paisagem"? De que modo o "sentimento da paisagem", registrado em fotografias e poesia, contribui com o processo de ensino desta categoria em Geografia?

Assim, estruturou-se os trilhos da abordagem pela formatação de uma sequência didática inicial, comportando-se como parâmetro para futuros ajustes/adequações. Neste ínterim, o sentimento da paisagem foi posicionado através da ação dos estudantes, por suas representações afetivas em seus espaços de estudo, tendo a fotografia como mecanismo de obtenção de imagens que dariam suporte à manifestação da poética escrita.

Pelos caminhos do estudo de caso, o Campus Avançado Guarantã do Norte, do Instituto Federal de Educação, Ciência e Tecnologia de Mato Grosso (IFMT), foi a centralidade espacial para o registro das imagens pelos estudantes.

Dessa maneira, foi possível discernir a construção efetiva no ensino por um aporte didático pautado em instrumentos interdisciplinares, assim como ratificar a fotografia e a poesia como mecanismos salutares para o desenvolvimento do aprendizado sobre a paisagem em Geografia. 


\section{REFERENCIAL TEÓRICO}

\subsection{Um Breve OVervieW Sobre A Paisagem}

A paisagem é uma categoria geográfica que apresenta os múltiplos processos sociais e ambientais em interação numa determinada espacialidade. Por ela é possível discernir vinculações históricas, dinâmicas naturais e composições ligadas aos contextos intencionais das sociedades.

Maximiano (2004, p. 83) caracteriza essa categoria da seguinte maneira:

Na Geografia ocidental contemporânea paisagem é entendida como produto visual de interações entre elementos naturais e sociais que, por ocupar um espaço, pode ser cartografada em escala macro ou de detalhe, e classificada de acordo com um método ou elemento que a compõe.

Guimarães (2002, p.120) amplia essa dimensão e indica que a paisagem:

[...] em suas múltiplas faces mescla-se com a vida, com o sonho, com o desejo de cada cultura, enquanto um único corpo. E então, novamente fragmenta-se para envolver uma gênese de atitudes e condutas, de formas e símbolos, de ciclos, movimentos, ritmos, de agir e não-agir, paisagens de um mundo fragmentado, plural, porque vivenciado sob diferentes cadências temporais.

Neste processo, a paisagem se configura como uma possibilidade, em termos de parâmetro, para configurar as múltiplas relações existentes entre o ser humano e o espaço. Este caminho, inicialmente, estabeleceu-se por indagações em diferentes contextos históricos, como a Antiguidade Clássica, Idade Média, Modernidade e Contemporaneidade, distinguindo-se desde os impactos do mundo externo às sociedades, às artes e a formatação sistemática inicial em Geografia por Alexander von Humboldt (MAXIMIANO, 2004; VERGES; BAUAB, 2016).

Salgueiro (2001, p.45), aponta que:

$\mathrm{Na}$ Geografia Humana verifica-se o acentuar do facto da paisagem ser um território visto e sentido, cada vez mais subjectivo e elaborado pela mente. $\mathrm{O}$ enfoque centra-se no indivíduo, nas suas práticas e nas representações que elabora do mundo exterior, as quais condicionam, por sua vez, o comportamento [...].

Por esta dimensão, é possível configurar dois grandes caminhos para as interpretações e composições em ensino para a paisagem, sendo uma pelas caracterizações das macroestruturas econômicas e políticas e outro pelas elucubrações dos sujeitos, dos lugares construídos e suas manifestações nas pessoas.

Dessa maneira, a perspectiva em que se centra este trabalho buscará expor a composição de um caso analítico em sala de aula (estudo de caso) que tratou da paisagem, configurando aproximações entre as abordagens críticas em Geografia e a dimensão do sentimento para a 
identificações de linhas incisivas no estudo dessa categoria, ou seja, na própria afirmação dos sujeitos e lugares.

\subsection{O Enfoque Estrutural E A InSERÇão Do "Sentimento Da PaisageM"}

Em seu processo de desenvolvimento, a Geografia escolar passou por determinadas influências teórico-metodológicas, dimensionando-se desde uma perspectiva clássica linear, com a memorização de aportes físicos e políticos dos espaços, até contrapontos como o da chamada Geografia Crítica, em que os aportes materialistas históricos ganharam destaques.

Vesentini (1994) aponta que o enfoque crítico nesta ciência foi de suma importância para o reenquadramento de temas e orientações teórico-metodológicas, uma vez que as dimensões estruturais das questões espaciais, agora, ganharam proeminência.

Por exemplo, ao invés de se tratar unicamente de localizações, fusos horários, latitudes, longitudes, (entre outros), passa-se a problematizar aspectos ligados aos impactos ambientais, a divisão internacional do trabalho e as estruturas produtivas que possuem orquestrações espaciais significativas (VENSENTINI, 1994).

Neste aspecto, em diferentes abordagens didáticas na literatura da área, a paisagem é observada como possibilidade expressa das estruturantes socioeconômicas e da cultura, resultados intrincados que partem da relação sociedade/natureza. Assim, alinhamentos deste viés teórico no ensino de Geografia angariou status de caminho analítico profícuo e suficiente para a compreensão do fenômeno "paisagem" no ambiente escolar.

Todavia, outros aspectos dessa categoria analítica são deveras importantes na formação social do estudante em sua percepção sobre as diferentes manifestações geográficas. Alguns autores como Tuan, (2011), Verges e Bauab (2016), Salgueiro (2001), indicam a importância de compreensão da paisagem pelos entremeios das ligações afetivas, ou seja, pelas estruturas dos lugares em afeições construídas pelos sujeitos sociais que se caracterizam em determinado locus.

Dessa maneira, o sentimento gerado pela interpretação da paisagem e o reconhecimento pelos discentes dos laços afetivos no lugar podem vir a assentir a elevação do aprendizado sobre a estruturas socioeconômicas preponderantes nas paisagens, contribuindo com o reconhecimento de vínculos históricos e pessoais que contrapõem, em muitos casos, as buscas homogeneizadas da globalização como perversidade, exposta por Santos (2000). 


\section{Metodologia}

Estabeleceram-se por recursos metodológicos para a execução do trabalho abordagens como: a) a formatação conceitual sobre a problemática da paisagem; b) a construção da propositiva em sala de aula; c) a análise dos dados obtidos, em que a disposição interpretativa dos materiais produzidos pelos estudantes marcou a evidenciação dos resultados.

Junto da necessidade de estruturar o ensino pela leitura geográfica da paisagem, houve o levantamento prévio em publicações já trabalhadas na instituição, versando sobre a temática, ao mesmo tempo em referenciais teóricos provindos da academia, que problematizam o elemento categórico em questão.

Neste caso, compreendendo que a paisagem revela facetas específicas que se somam às orientadas por processos econômicos e/ou políticos em linhas macro-estruturais (TUAN, 2011), procurou-se posicionar uma perspectiva que apresentasse a leitura da paisagem como forma de percepção adjunta do lugar na observação geográfica.

Por este aspecto, as vinculações do sentimento humano pelo espaço habitado se apresentaram como mandatórias e, para isso, um importante instrumento provindo das artes para a reflexão foi a conjugação "imagem e poética" pela elaboração direta de fotografias e poesias sobre a própria paisagem.

Assim, coube a construção de uma sequência educacional em que fosse possível compreender aspectos estruturais das paisagens, mas, assomadamente, perceber como ela revela os significados e a inserção dos indivíduos nas diferentes territorialidades que nos cercam.

Dessa forma, encaminhou-se o trabalho em seis aulas de 50 minutos cada, instrumentalizando o reconhecimento da paisagem pelo caminho da fotografia, pela descrição socioeconômica do momento/espacialidade em registro e, por fim, a elaboração de uma poesia que descrevesse as conjunturas posicionais do sujeito estudante perante o momento focalizado.

Para a compreensão do material elaborado pelos discentes, caracterizou-se a aferição das palavras-chaves decorrentes dos aportes socioeconômicos e poéticos redigidos por estes em textos e poesias. Tendo isto enfocado, utilizou-se a ferramenta "Nuvem de Palavras", em que é facilitada a disposição dos principais termos e caminhos elucidativos apontados pelos alunos em suas escritas.

Neste contexto, o software wordclouds.com foi a ferramenta quantitativo/expositiva das construções narrativas geradas pela abordagem sobre as paisagens no decorrer das aulas, permitindo a análise específica. 
Especificamente, buscou-se com a nuvens de palavras quantificar os termos utilizados para expressar as ideias contidas nos textos sugeridos. Com isso, foi possível, através do padrão escrito, compreender quais as nuances conceituais e textuais indicadas como significados pelos estudantes. Num outro aspecto, procurou-se discernir com a comparação entre os resultados conceituais a efetividade da vinculação entre disposição estrutural e subjetiva para a ampliação do ensino sobre a paisagem junto a disciplina de Geografia, ratificando a concepção de aula e os instrumentos utilizados.

\section{Resultados}

\subsection{Crítica E "Sentimento Da Paisagem": Uma Proposta De Ensino}

Neste item, propõe-se a disposição da sequência didática construída para o trabalho com a paisagem e, conjuntamente, a exposição analítica do material obtido com a ação, advindo da produção dos estudantes.

Assim, em dinâmica de aula, a partir do intento acima evidenciado, foi proposto aos estudantes do segundo ano do curso Técnico em Agropecuária Integrado ao Ensino Médio que fotografassem elementos da paisagem ao redor da instituição educacional e, com as imagens, estabelecessem dois meios interpretativos/descritivos: a) a crítica socioeconômica; b) poesia sobre a paisagem registrada.

O Campus em que os alunos desenvolveram suas atividades de aprendizagem possui o caráter agropecuário, sendo instaurado numa área com 50 hectares. Neste local, existia um seminário católico, da Ordem dos Padres Cavanis. Após a transferência deste centro de formação religiosa para outro local, o terreno foi cedido pela Prefeitura para o Instituto Federal de Educação, Ciência e Tecnologia de Mato Grosso (IFMT). Neste cenário de estudos técnicos e superiores, existem os cursos e estruturas para o Bacharelado em Zootecnia, Tecnologia em Agroindústria, Licenciatura em Ciências da Natureza - Habilitação em Biologia e Técnico em Agropecuária Integrado ao Ensino Médio.

Desse modo, no ambiente de ensino, para além das manifestações econômicas da paisagem, existem aportes estruturais, culturais e sociais demarcados, o que permite ampliar as análises geográficas pelos estudantes (CALLAI, 2005).

Por este viés, foram separados grupos com até quatro integrantes e estes se direcionaram pelo campus com a finalidade de registrar naquele ambiente uma imagem que apresentasse 
significado afetivo para eles e, ao mesmo tempo, permitisse leituras críticas. Para isto, foram utilizados os aparelhos celulares dos envolvidos e câmeras fotográficas, sendo que o grupo poderia apresentar uma única imagem ou imagens individuais para cada membro do grupo.

Esta sequência em ensino demarcou o total de seis aulas, sendo que duas delas foram tomadas pelo trabalho a campo das fotografias, com análise conjunta delas pelo professor e discentes em sala de aula, após os registros. As outras quatro aulas compuseram dois blocos, com um momento para a abordagem crítica - socioeconômica - e outro demarcando as notações poéticas.

Dessa maneira, foram produzidas fotografias como as que seguem abaixo:

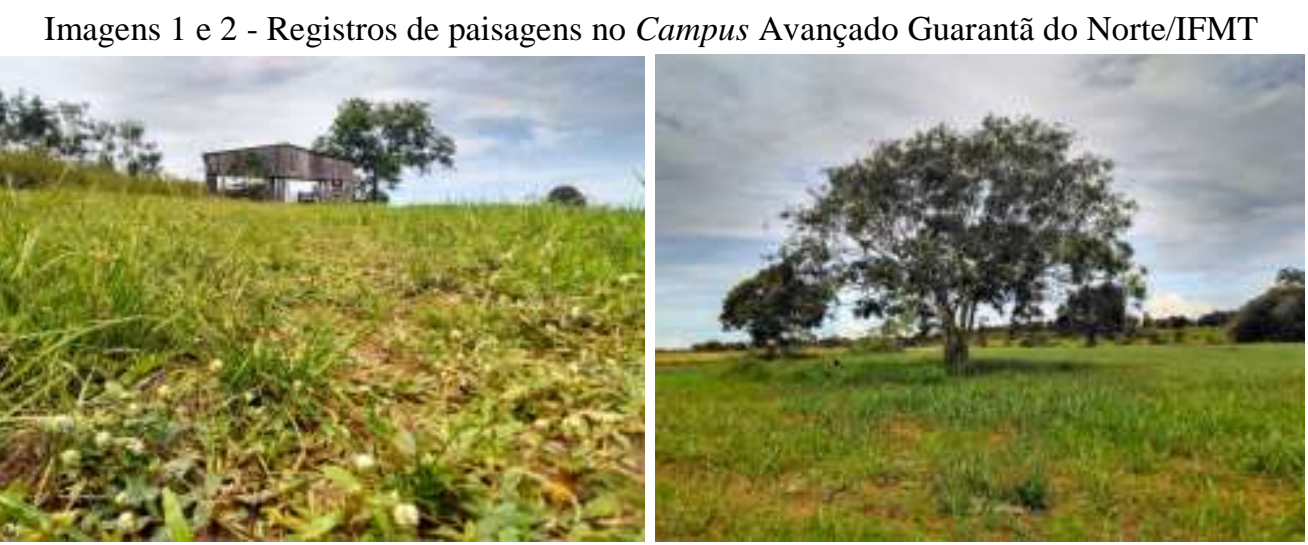

Fonte: Fotografias levantadas em aula por estudantes do curso Técnico em Agropecuária Integrado ao Ensino Médio - IFMT/Campus Avançado Guarantã do Norte.

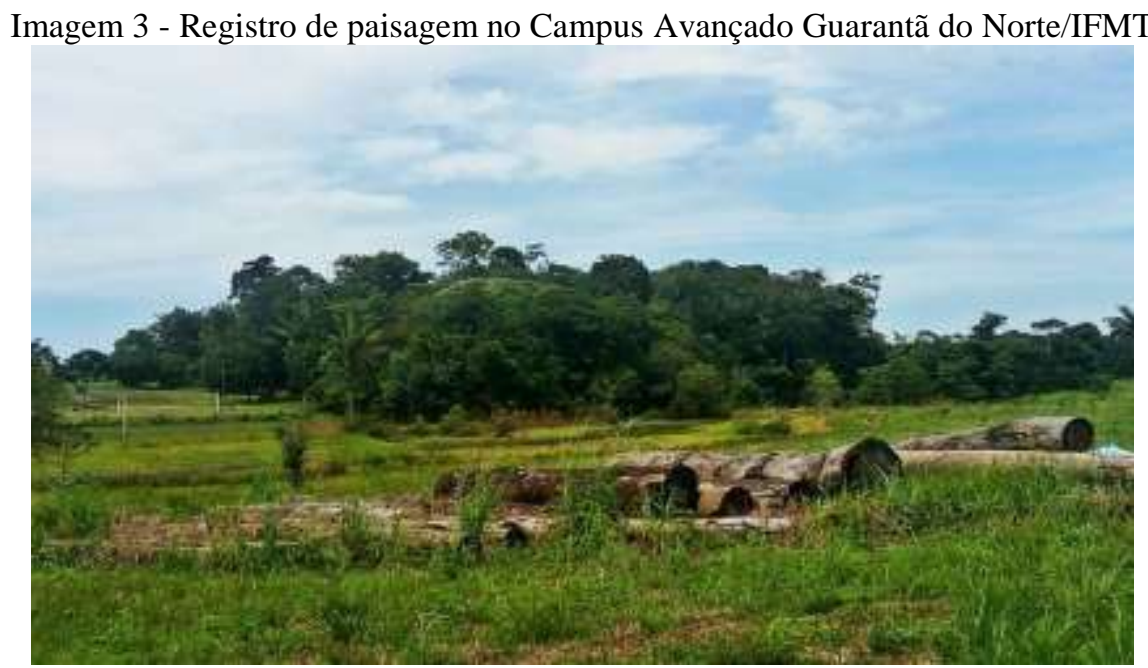

Fonte: Fotografias levantadas em aula por estudantes do curso Técnico em Agropecuária Integrado ao Ensino Médio - IFMT/Campus Avançado Guarantã do Norte.

Com isto, foram elaboradas reflexões e posicionamentos que podem, aqui, serem traduzidos em palavras-chaves. Para este fim, utilizou-se da ferramenta Cloud Word, expressando quais foram os principais eixos analíticos posicionados pelos estudantes. 
Figura 1 - Termos mais utilizados pelos estudantes para a análise crítica

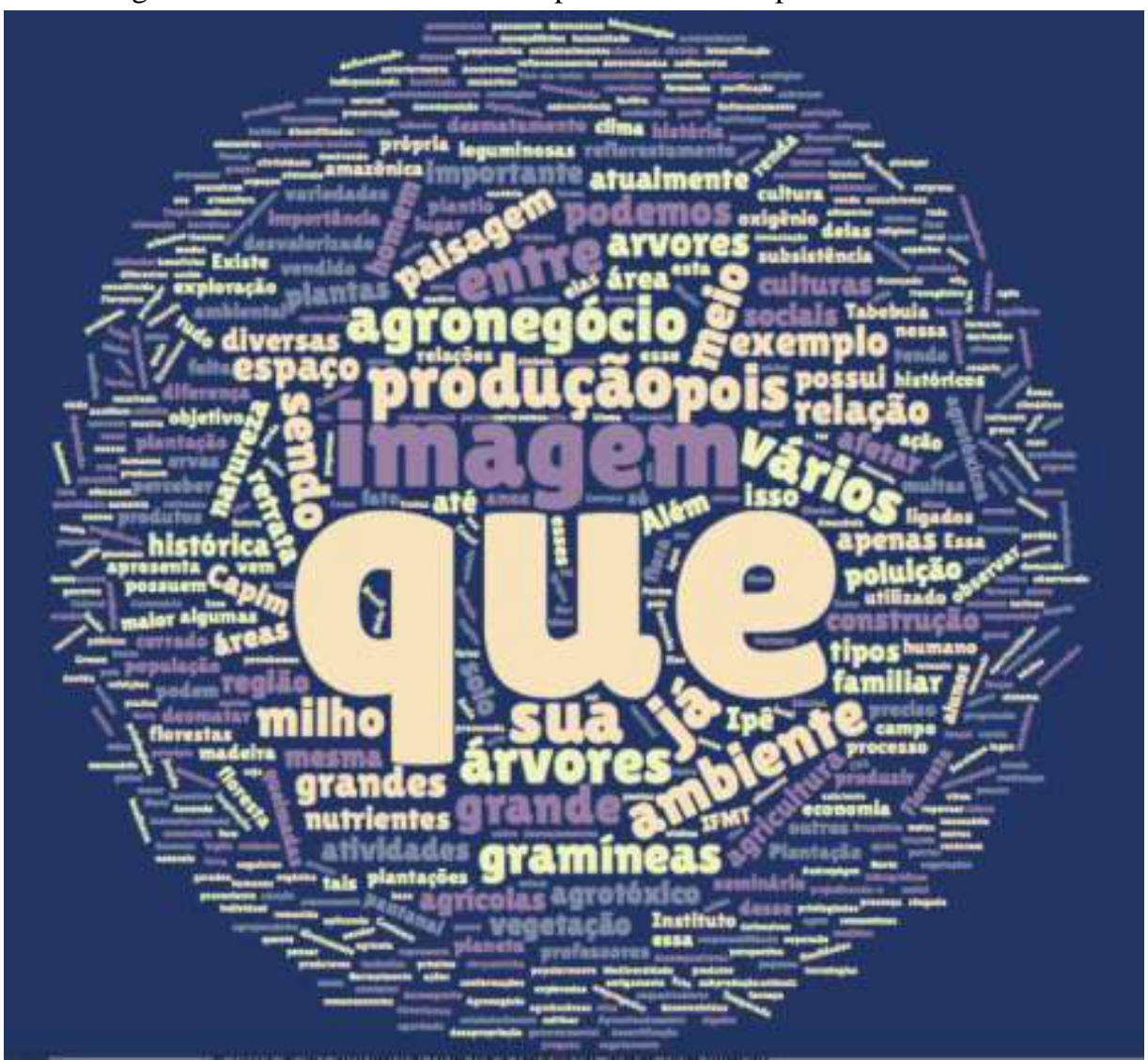

Fonte: Textos produzidos pelos estudantes para análises críticas da paisagem/Software: wordclouds.com

Pode-se notar que as compreensões relativas às paisagens a partir do viés crítico pautado nas linhas sociais e econômicas foram guiadas por expressões como "produção", "agronegócio", "meio", “Ambiente”, "nutrientes" e demais referenciais de abordagem que estão diretamente vinculados aos escopos produtivos. Em linhas amplas, parte importante das abordagens em sala de aula, seja na prática autônoma ou em livros didáticos, costuma fixar centralidade neste atrelamento junto da paisagem (CALLAI, 2005).

De acordo com Schier (2003), a abordagem crítica em Geografia relegou à paisagem um caráter secundário, marcado pela afirmação estrutural dos movimentos econômicos capitalistas, em que a ação das intencionalidades produtivas é que comportaria - quase que unicamente - a geração e recriação das paisagens.

Entretanto, o sentimento da paisagem é um dos elementos chaves na compreensão de processos geográficos que se instalam no lugar (VERGES; BAUAB, 2016). Neste ínterim, a concentração na faceta econômico-social da paisagem pode apresentar determinada limitação, ou seja, a de que as territorialidades seriam compostas unicamente pelos interesses econômicos, negando o lugar. 
Já com a dinâmica complementar da análise da paisagem pela poética, demonstrada pelos estudantes através da elaboração de poesias, foi possível observar um salto analítico com relação ao enfoque dos trabalhos, em que as expressões associadas às descrições não se fundamentaram unicamente nos caracteres da produção e ações majoritariamente provindas da economia, mas sim nas significações humanas dos lugares.

Dessa forma, tem-se abaixo a nuvem de palavras que marca as inclinações poéticas dos estudantes sobre o assunto disposto:

Figura 2 - Termos mais utilizados pelos estudantes nas poesias elaboradas.

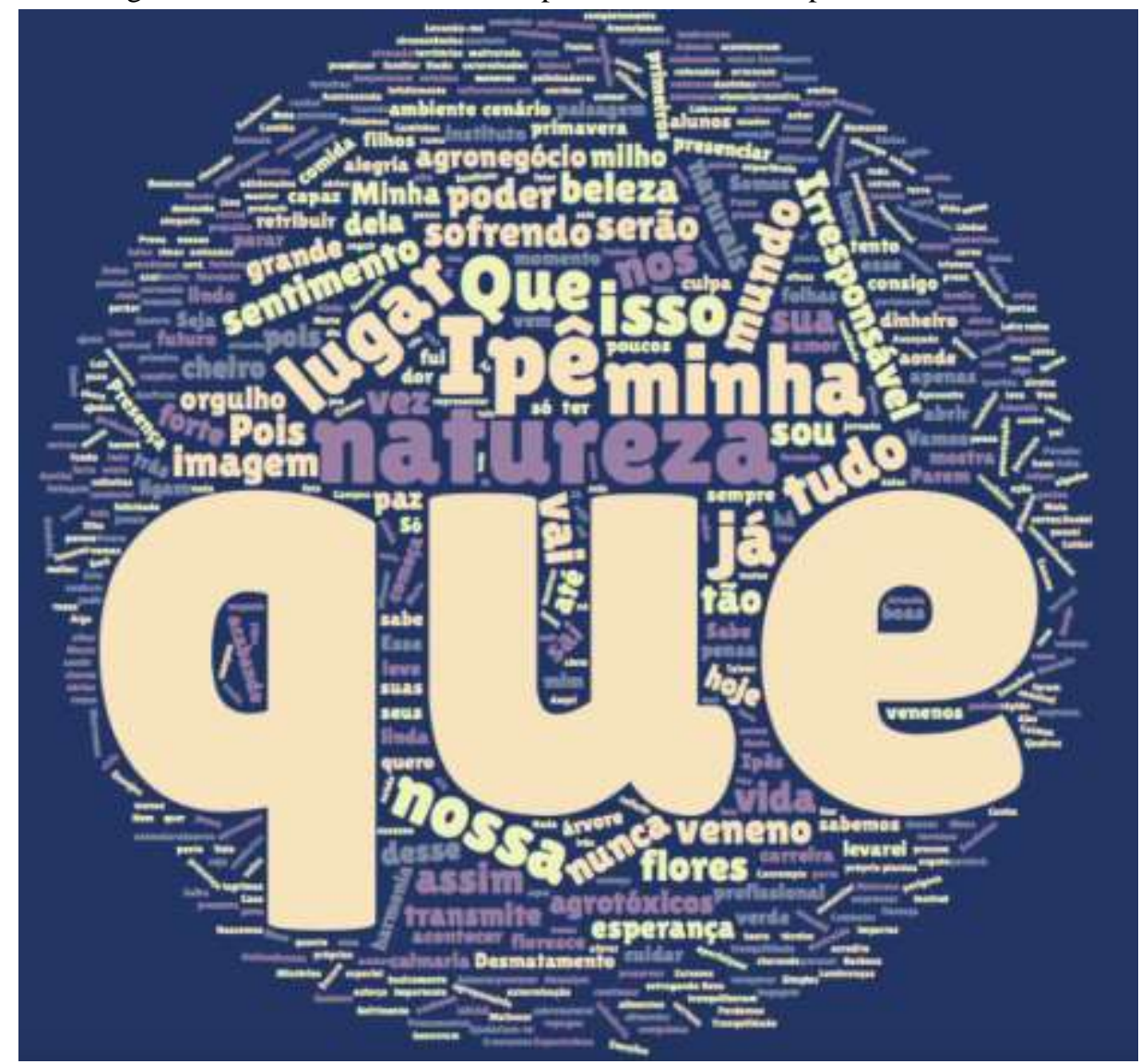

Fonte: poesias produzidas pelos estudantes sobre as paisagens fotografadas/Software: wordclouds.com

Como se observa, termos como "natureza", "lugar", "minha", "nossa”, “sou”, "mundo" passam a compor um dos possíveis significados analíticos para as mesmas paisagens que retratavam, sobretudo, os impactos do agronegócio.

Neste processo, o reconhecimento do espaço geográfico é complementado com as demarcações gerais dos aportes sobre a relação sujeito/natureza no que corresponde aos significados, as marcas culturais, pessoais (PUNTEL, 2007). 


\title{
4.2. As Significações Sobre As Relações Sociedade/Natureza Pela Paisagem No EnSINO De GEOGRAFIA
}

O ensino de Geografia, de acordo com os Parâmetros Curriculares Nacionais (PCN`s), se coloca ancorado em determinados pilares, conferindo que:

\begin{abstract}
"[...] é importante pensar o estabelecimento de relações através da interdependência, da conexão de fenômenos, numa ligação entre o sujeito humano e os objetos de seus interesses, na qual a contextualização se faz necessária (PEREIRA; ROMERO, 2000, p.29).
\end{abstract}

Os sujeitos históricos, mobilizadores de colocações políticas e entendimentos econômicos estruturais se apresentam como parte importante do processo de interpretação e aprendizagem quando do estudo sobre categorias geográficas. Contudo, é necessário manter a aproximação com o "sujeito humano" citado nos PCN`s, indivíduo este que, socialmente, se encontra em determinado lugar, com suas significações, orientações, sentimentos e visualizações.

Com os resultados expostos neste estudo de caso em sala de aula, é possível compreender que a proposição pela interpretação de uma imagem fotográfica no ato de redigir poesia confere ao estudante a oportunidade de descrição e análise da paisagem a partir dos elementos humanos e dos significados individuais que se encontram na coletividade social.

O trabalho unicamente pela expressão do capital nas paisagens, mensurando as rugosidades temporais no movimento macro-histórico, pode posicionar a compreensão desta categoria em Geografia por uma das facetas que ela, em si, carrega, o que seria, de algum modo, empobrecedor; no mesmo compasso, a veiculação de observações poéticas em paisagens nunca vividas, experimentadas, poderá não produzir efeitos satisfatórios em comparação com os obtidos na inclinação sobre espaços do cotidiano, ou seja, os lugares, fotografados como na seqüência didática narrada e poetizados à luz das sensações diárias que conduzem na vida dos estudantes.

Neste sentido, os caminhos orientadores iniciais da proposta - como estruturar uma aula apoiada no "sentimento da paisagem"? De que modo o "sentimento da paisagem", registrado em fotografias e poesia, contribui com o processo de ensino desta categoria em Geografia? - puderam ser configurados e respondidos. Inicialmente, o movimento de construção da sequência didática é, ao mesmo tempo, caminho e processo que permite verificar sua aplicabilidade. Entende-se que a elaboração da seqüência apresentou, conjuntamente, a possibilidade de teste e, com ela, a resposta ao segundo questionamento. 
Por fim, a fotografia e a poesia contribuem para que se crie uma dinâmica de observação do lugar no espaço para os estudantes, ou seja, garante que estes possam interpretar a paisagem que os cercam, refletir sobre os próprios cotidianos e como tais constatações se organizam e participam de diferentes escalas, sendo elas macroestruturais (econômicas e políticas) ou pessoais, com suas significações junto da individualidade e dos entremeios sociais. Isto corrobora trabalhos como Dos Santos e Chiapetti (2011) e Costa e Benites (2009), procurando dimensionar o papel de instrumentos comunicacionais no ensino de Geografia.

\section{CONSIDERAÇões FINAIS}

Este trabalho buscou expor resultados e reflexões sobre o processo de ensino na disciplina de Geografia. A partir de reflexões levantas em pesquisa, aportou-se na elaboração de uma proposta metodológica, aplicada e disposta para as análises.

A forte contribuição de leituras críticas no contexto da Geografia acaba por posicionar a paisagem, nos âmbitos da apreensão escolar, sobre as égides macroeconômicas e/ou políticas. Com isso, salutares se fazem as buscas por enquadramentos dos sujeitos e suas significações no ato de lecionar categorias geográficas.

Assim, foi possível compreender que a interligação entre crítica e poesia, apoiadas no instrumento fotográfico, assente o aparecimento de conclusões mais alargadas pelos estudantes, visto as enumerações conseguidas com o trabalho.

\section{REFERÊNCIAS}

CALLAI, Helena Copetti. Aprendendo a ler o mundo: a geografia nos anos iniciais do ensino fundamental. Cad. Cedes, Campinas, v. 25, n. 66, p. 227-247, 2005.

COSTA, Moisés Meira; BENITES, Miguel Gimenez. Realismo na fotografia: um ensaio sobre o estudo da linguagem fotográfica para o ensino de geografia. Título Páginas, p. 455, 2009.

DOS SANTOS, Rita de Cássia Evangelista; CHIAPETTI, Rita Jaqueline Nogueira. Uma investigação sobre o uso das diversas linguagens no ensino de Geografia: uma interface teoria e prática. Geografia Ensino \& Pesquisa, v. 15, n. 3, p. 167-184, 2011.

GUIMARÃES, S.T.L. Reflexões a respeito da paisagem vivida, topofilia e topofobia à luz dos estudos sobre experiência, percepção e interpretação ambiental. Geosul, v. 17, n. 33, p. 117$142,2002$.

MAXIMIANO, L. A. Considerações sobre o conceito de paisagem. Raega-O Espaço Geográfico em Análise, v. 8, 2004. 
PEREIRA, Simões; ROMERO, Avelino. Ciências Humanas e suas Tecnologias. Parâmetros curriculares nacionais, ensino médio;, 2000.

PUNTEL, Geovane. A Paisagem no ensino da Geografia. Ágora, v. 13, n. 1, p. 283-298, 2007 SALGUEIRO, T. B. Paisagem e geografia. Finisterra, v. 36, n. 72, 2001.

SCHIER, Raul Alfredo. Trajetórias do conceito de paisagem na geografia. Raega-O Espaço Geográfico em Análise, v. 7, 2003.

TUAN, Y. F. Espaço, tempo, lugar: um arcabouço humanista/Space, time, place: a humanistic frame. Geograficidade, v. 1, n. 1, p. 4-15, 2011.

VERGES, J. V. G.; BAUAB, F. P. A Transdisciplinaridade da Ciência de Alexander Von Humboldt (1769-1859): Intersecções junto aos Debates Contemporâneos sobre o Conhecimento. Boletim de Geografia, v. 33, n. 3, p. 17-30, 2016.

VESENTINI, J. W. Geografia e ensino: textos críticos. Papirus Editora, 1994.

Recebido em: 30 de janeiro de 2018. Aprovado em: 22 de setembro de 2018. 